Poster Section

\title{
Pilot study of preventive homeopathic treatment for colibacillosis in a swine farm in the state of São Paulo, Brazil
}

\author{
Cidéli de Paula Coelho ${ }^{1,2,3}$, Francisco Rafael Martins Soto ${ }^{4}$, \\ Erlete Rosalina Vuaden ${ }^{5}$, Priscilla Anne Melville ${ }^{1}$, \\ Leoni Villano Bonamin 2,3 , Nilson Roberti Benites ${ }^{1}$
}

\author{
${ }^{1}$ College of Veterinary Medicine and Animal Sciences, University of Sao Paulo (USP), Brazil \\ ${ }^{2}$ Faculty of Veterinary Medicine, Paulista University (UNIP), Brazil \\ ${ }^{3}$ Santo Amaro University (UNISA), Brazil \\ ${ }^{4}$ Center for Sanitary Surveillance and Zoonoses Control “Tereza R. de Camargo", Brazil \\ ${ }_{5 \mathrm{M}}$ Cassab- Animal Technology, Brazil
}

\begin{abstract}
Background: Diarrhea has become an economically important disease in pigs due to intensive management system which has been used. Escherichia coli is the most important etiological agent of neonatal and post weaning diarrhea in swine colibacillosis and the greater impact of the disease in pigs. The demand of consumers seeking meat without chemical residues and the prohibition of the use of antibiotics and chemotherapeutics in swine production has led to seek an alternative medicine for preventive and therapeutic treatments in swine breeding. The objective of this study was to evaluate the effectiveness of prophylactic treatment for diarrhea swine using homeopathic medicine, Escherichia coli biotherapic and search experimental evidence that may indicate the use of $E$. coli biotherapic. To evaluate the difference in weight gain of the pigs in groups and this gain is increased with less toxic.
\end{abstract}

Methods: This study was carried out in a commercial farm in São Paulo state. Stool samples were collected from five piglets presenting diarrhea and examined for the presence of Escherichia coli with these strains were made Biotherapics for later use. Concomitantly, a detailed interview was done with the owner, about all clinical information useful to choose the best homeopathic medicine, using repertory method. Subsequently, four groups were formed consisting of 11-12 piglets each: a control group (antimicrobial used in the farm routine for treatment of diarrhea), a group treated with the chosen homeopathic medicine - China officinalis $30 \mathrm{CH}$ [1](Cinchona officinalis) - a group treated with E. coli biotherapic $30 \mathrm{CH}$ (medicine made from $E$. coli strains collected and isolated from the same farm) and a group treated with both homeopathic and E. coli biotherapic medicines.

Results: There was no statistical difference in the number of animals presenting diarrhea among groups, but China treated pigs showed greater weight gain compared to the other three groups (Fisher test, $\mathrm{p}=0.0001$ ), despite the incidence of diarrhea. (tables 1 and 2) 
Conclusion: This preliminary study suggests that the use of homeopathic medicines could improve productivity in swine farms even though clinical manifestations of diarrhea occur.

Keywords: homeopathy, E.coli, biotherapic, pigs.

\section{Reference:}

[1] Kent JT. Repertory of the homoeopathic materia medica. India: B. Jain Publishers, 2006: 1542 p.

Table 1 - Number of animals with diarrhea at the beginning and the end of treatment.

\begin{tabular}{|l|c|c|}
\hline Group & $\begin{array}{c}\text { Beginning (number of sick } \\
\text { animals) (\%) }\end{array}$ & $\begin{array}{c}\text { End (number of sick } \\
\text { animals) (\%) }\end{array}$ \\
\hline E. coli biotherapic $30 \mathrm{CH}$ & $2(16.6 \%)$ & $5(41.6 \%)$ \\
\hline China off + biotherapic $30 \mathrm{CH}$ & $1(8.3 \%)$ & $0(0)$ \\
\hline China off $30 \mathrm{CH}$ & $3(25.0 \%)$ & $0(0)$ \\
\hline Control group & $1(9.0 \%)$ & $2(18.1 \%)$ \\
\hline Total number of animals & 47 & 43 \\
\hline
\end{tabular}

Table 2 -Weight average at the beginning of treatment and weaning.

\begin{tabular}{|l|c|c|c|}
\hline Group & $\begin{array}{c}\text { Beginning (Average } \\
\text { weight/ number of } \\
\text { animals) }\end{array}$ & $\begin{array}{c}\text { Weaning (Average } \\
\text { weight/ number of } \\
\text { animals) }\end{array}$ & $\begin{array}{c}\text { Average } \\
\text { weight } \\
\text { again }\end{array}$ \\
\hline E. coli biotherapic $30 \mathrm{CH}$ & $1116(12)$ & $3627(12)$ & $2511^{* *}$ \\
\hline China off + biotherapic $30 \mathrm{CH}$ & $1950(12)$ & $6416(8)$ & 4466 \\
\hline China off $30 \mathrm{CH}$ & $1107(12)$ & $6100(12)$ & $4993^{*}$ \\
\hline Control group & $1600(11)$ & $6000(11)$ & 4400 \\
\hline Total of animals & 47 & 43 & \\
\hline
\end{tabular}

* Fischer's Test, $\mathrm{p}=0.0001$, regarding all 3 other groups.

** Fischer's Test, $\mathrm{p}=0.001$, regarding Control group.

\section{(c)) BY-NC-ND Licensed to GIRI}

Support: authors declare that this study received no funding

Conflict of interest: authors declare there is no conflict of interest

Received: 01 June 2012; Revised: 07 August 2012; Published: 30 September 2012.

Correspondence author: : Cidéli de Paula Coelho, ccideli@uol.com.br.

How to cite this article: Coelho CP, Soto FRM, Vuaden ER, Melville PA, Bonamin LV, Benites NR. Pilot study of preventive homeopathic treatment for colibacillosis in a swine farm in the state of São Paulo, Brazil. Int J High Dilution Res [online]. 2012 [cited YYYY Month dd]; 11(40):159-160. Proceedings of the XXVI GIRI Symposium; 2012 Sep 20-22; Florence (Italy). GIRI; 2012; Available from: http://www.feg.unesp.br/ ojs/index.php/ijhdr/article/view/592/565 